\title{
An Analysis Framework of the Relationship between R\&D Resources and Innovation Performance
}

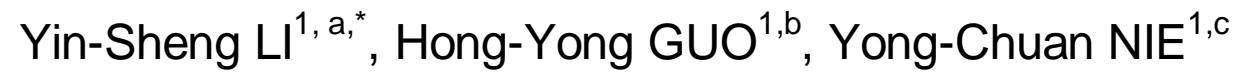 \\ ${ }^{1}$ Hebei Science \& Technology Information Institute, Shijiazhuang, China \\ ays11965@126.com, hebsts@163.com, nieyongchuan@163.com \\ ${ }^{*}$ Corresponding author
}

Keywords: R\&D Resources, Innovation performance, Framework.

\begin{abstract}
This paper argues that it is a complex systematic process from the R\&D resource to realize the innovation performance. The relationship between the $R \& D$ resources and innovation performance is closely linked with this complex process. It proposed the theory analysis framework about the relationship from $\mathrm{R} \& \mathrm{D}$ resources to innovation performance, and elaborated the relationship involved in the process.
\end{abstract}

\section{Introduction}

In 1912, Joseph A. Schumpeter for the first time put forward the concept of "Innovation"[1], In 1956, Robert Solow and T.W.Swan put forward the "Solow-Swan" Model[2,3], the model considers that technological progress's contribution to the economic growth is the most important, and is an independent factor of promoting economic growth. In the last century the 80s, Paul M. Romer and Robert Lucas, established the theory of endogenous economic growth [4,5] .

The endogenous economic growth theory argues that technology $(R \& D)$ activities is the endogenous variable of economic growth, knowledge accumulation is a motive force of the economic growth, and $R \& D$ activities is the main way of knowledge accumulation, $R \& D$ activities promoted the accumulation of knowledge and economic growth. R\&D activities promoted the accumulation of knowledge and economic growth. Its main conclusion is: economic growth is determined by the endogenous variable of economic system; Endogenous technological progress - the level of human capital and R\&D capital levels of growth is the decisive factor for economy to achieve sustained growth.

\section{Analysis Framework}

About the relationship between $R \& D$ resources and the innovation performance, has been a tireless pursuit of the theoretical research hot spot. This paper argues from R\&D resources to realize the innovation performance is a many levels, multiple links complex systematic process, the relationship between R\&D resources and innovation performance and the complex process is closely linked. In order to express this point of view, this paper builds a theoretical framework, and analyzes the relationship between them. (See figure 1)

\section{Opinions:}

First. $R \& D$ resources is the core of science and technology resources, is the foundation of support R\&D activities. Endogenous economic growth theory proved that the R\&D resources has the attributes of knowledge, so as to have a part attribute of the Public Goods, namely the Non - rivalry in consumption and Non-exclusion in consumption, which makes the R\&D resources have spillover effect, and the existence of Spillover effects makes R\&D resources had the diffusivity and liquidity, which provide the conditions to makes the results of $R \& D$ activities can be blend into social and economic fields. 


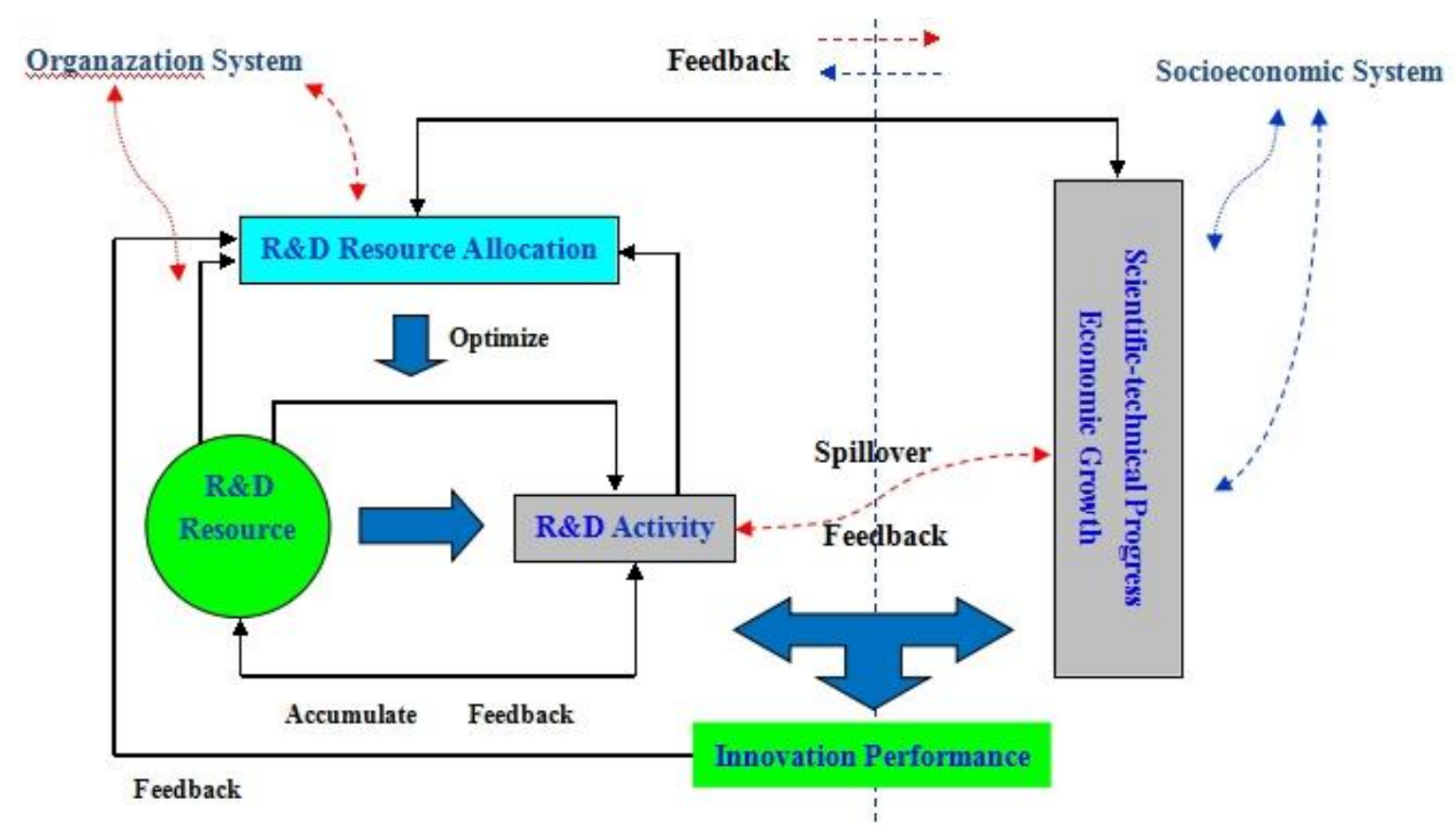

Fig. 1 The sketch map of the relationship between $R \& D$ resource and innovation performance

Second. R\&D activities is one kind of technical activities which utilizing R\&D resources, its biggest characteristic is creativity and novelty. Within the organization R\&D activities is characterized by two aspects, on the one hand, promoted the organization's ability to learn through R\&D activities, namely the ability of using of knowledge resource $(R \& D)$ to found and solve the problem, then promote the technological innovation and economic growth of organization, on the other hand, R\&D activities, in turn, promote the $R \& D$ resources (knowledge), main show is the increasing of $R \& D$ (knowledge) stock within the organization; For external, $R \& D$ activities through technical innovation and $R \& D$ resources spillover effect behavior blend in social and economic fields, main show is the technological progress and economic growth in the social economic and scientific technological system, the results of this series of actions, is the innovation performance of $R \& D$ resources. The technological progress in the socioeconomic system of scientific and the change of economic growth, which in turn will put forward new requirements on $\mathrm{R} \& \mathrm{D}$ activity, and then to form upward spiral through a variety of link channels.

Third. R\&D resource allocation is kind of deploy about the elements of R\&D activities in space-time, is the optimum combination of $R \& D$ resources. It is affected by the $R \& D$ resources itself, the characteristics of R\&D activities, organization management mode of social and economic systems and the feedback information and so on many factors, so it is a complex process.

In a larger organization, such as national level, the main mode of $R \& D$ resource allocation can be divided into three categories. One is dominated by the free market in the United States, the government is account for only a secondary position in the allocation of $R \& D$ resources, market demand is the dominant factor of $R \& D$ resource allocation in the American model; Secondly, Germany's social market economy model, the main characteristics of the German model is that it considers R\&D resource allocation should not be completely determined by the market, the government can appropriate intervention. A third is Japan's community market economic model, it is administrative guidance, the Japanese model tend to think the government can direct investment on R\&D of utilities to create conditions for private capital, and through a variety of preferential policies to guide the social investment in R\&D field.

How to choose what kind of $R \& D$ resource configuration mode in a regional scale, in addition to take into account of the government orientation and market orientation, also should consider the resources endowment of regional differences and characteristics of industrial structure and regional social and cultural background; Within a relatively small organization system, such as industry, or enterprise internal, $R \& D$ resources configuration mode is affected by industry characteristics and the influence of 
value orientation within the organization, so for the $R \& D$ resource allocation evaluation is a multifactor decision-making process.

Fourth. From $R \& D$ resources to $R \& D$ activities to $R \& D$ resources to innovation performance (economic growth), is a more complicated process, multiple links. First, the R\&D resources provided material guarantee for the $R \& D$ activities, $R \& D$ activities are based on the $R \& D$ resources to carry out innovative activities, $R \& D$ resources allocation is to optimize input factors which involved in the process of the innovation activities, and relationship between these three are closely connected and the existence of the feedback path, and thus constitute the subsystem of internal organization system ;Second, as a subsystem of organization, inevitably influenced by organization system factors, and this influence is mutual; Third, R\&D activities turn into the field of production and economic system through the spillover effect etc,. and promote social progress and economic growth, as the main form of expression of the process, innovation performance, will be closely combined with the process, and also the effect of the innovation performance will be feed back tot he subsystem through feedback system, it reflects the multiple links and of the process; Fourth, organization system is a subsystem of the social economic system and are influenced by social and economic system, this is the mutual effect. The social and economic system change affect the accumulation of $R \& D$ resources through the innovation performance, he allocation of resources and $R \& D$ activities, so as to the process is quite complex.

Fifth. R\&D resources structure and innovation performance has multidimensional characteristics, from the $R \& D$ resources to innovation performance is a complex process, and thus require us to investigate $R \& D$ resources, $R \& D$ activities and $R \& D$ resources configuration must be from the multi-scale and systemic perspective to describe the complex process. Do not use any macros for the figures and tables. (We will not be able to convert such papers into our system).

\section{Summary}

This paper reviewed the theory of technological innovation and economic growth, on the basis of this puts forward the theoretical framework for the R\&D resources and innovation performance, analyzed the $R \& D$ resources, $R \& D$ resources allocation, $R \& D$ activities, and the relationship between the technological progress and economic growth. It considered that from $R \& D$ resources to $R \& D$ resources to $R \& D$ activities and innovation performance (economic growth) is a more complicated, multiple-link process.

\section{Acknowledgement}

This research was financially supported by the Hebei province science and technology plan.

\section{References}

[1] Schumpeter,J.A. The Theory of Economic Development :An Inquiry Into Profits, Capital, Credit, Interest, and the Business Cycle [M]. Translated From the German by Redvers Opie, 1961).

[2] Robert M.Solow.A Contribution to the Theory of Economic Growth[J].

[3] T.W.Swan, Economic growth and capital accumulation, Economic Record, 1956, 32(63): 334-361.

[4] Omer Paul M.Increasing Returns and Long Run Growth[J].Journal of Political Economy, 1986,(94):1 002-1037).

[5] Robert E.Lucas Jr.On the mechanics of economic development[J]. Journal of Monetary Economics, 1988, (22): 3-42. 